\title{
College Students' Current Status of Metacognitive Accuracy and Its Implications
}

\author{
Pyong Ho Kim \\ Assistant Professor, Department of Educational Psychology \\ Seoul Women's University, Seoul, South Korea \\ phkim@swu.ac.kr
}

\begin{abstract}
College students show tendency of becoming either overconfident or underconfident regarding their examination performances. It demonstrates a low level of metacognitive accuracy. This research investigated how accurately college students, particularly freshman pre-service teachers of early childhood education department in South Korea, predict their performance prior to two major exams during a semester. The major rationale of the study is to foster students' metacognition in higher education. 48 freshmen pre-service teachers participated in the study online, with two study tools implemented: namely, a question survey and an open-ended questionnaire. The results showed that the student participants' prediction on final exam was more accurate than that of midterm exam, showing moderately improved metacognitive accuracy, with a few exceptions. This paper suggested a few implications for higher education instructors regarding how to successfully implement metacognitive methods in class settings based on the findings.
\end{abstract}

Keywords: Metacognition, Metacognitive accuracy, Monitoring, Higher education

\section{Introduction}

\subsection{Background of the study}

The absolute majority, if not all, of educational psychology researchers honor John H. Flavell as a pioneer who opened a new prospect in the field of metacognition in the late 1970's from his classic article: Metacognition and Cognitive Monitoring (1979) [1]. Metacognition, whose literal translation means comprehensive thinking, refers to a cognitive method of "thinking about thinking" in which individuals reflect on their own thinking process. Flavell argued that it comprises "any conscious cognitive or affective experiences that accompany and pertain to any intellectual enterprise" (p.906). In other words, a high level of metacognition may indicate that individuals being accurately aware of themselves when it comes to learning and performing; it would lead to better metacognition if one knows himself or herself subjectively, as if a third-party individual observes.

Metacognition plays an essential role in learning environment (e.g., classroom), because knowledge about an individual's learning affects future study choices as well as his or her learning [2][3]. These emphasize the importance of a high level of metacognition (i.e., truthfully evaluating one's own status). However, most individuals find it challenging to accurately judge their own knowledge or performance levels. For a non-academic example,

Article history:

Received (January 12, 2021), Review Result (February 17, 2021), Accepted (March 27, 2021) 
when lawyers are asked to predict a trial's result, they tend to display overconfidence, and such phenomenon is observable even among lawyers who practiced for up to 40 years [4]. Similarly, a notable problem that Flavell and his colleagues identified was that student learners who participated in their study were often mistaken that they had successfully memorized given items, but were not actually able to recall them [5]. Such outcomes result in having students attain either over or under-confidence, making it difficult for them to properly prepare for exams, for example. Callender et al. (2016) underlined that one goal of researching in metacognition is to further understanding of fundamental mechanisms involved in reducing discrepancies between judgments and performance [6]. In order to achieve the goal, the first step would be estimate student learners' current status of metacognitive levels. Thus, one goal that the paper seeks to achieve is measure student learners' metacognitive accuracy (i.e., to what extend they are aware of their own learning performance).

The terminology of metacognition can also be described as "systematic frameworks used to explain and direct cognition, metacognitive knowledge, and regulatory skills" [7]. The following paragraphs describe the metacognitive skills' two major functions known: namely the knowledge of cognition and the regulation of cognition.

The knowledge of cognition refers to what learners recognize about their own cognition. According to Schraw and Moshman (1995) [7] the knowledge of cognition consists of three components: namely (1) declarative knowledge, (2) procedural knowledge, and (3) conditional knowledge. Declarative knowledge refers to individuals' ability to deliver certain knowledge; its examples include being able to explain the principles of earth's rotation and revolution. Procedural knowledge refers to knowing how to perform certain tasks, such as riding a bicycle, baking bread, and making beds. Conditional knowledge refers to knowing when and why to implement the declarative and procedural knowledge. Individuals who are equipped with a proper level of conditional knowledge should be able to suitably distribute the resources they have when using the strategies for efficient procedures and successful outcomes [5]. Even when individuals have both declarative and procedural knowledge, these resources would not work effectively if they have a low level of conditional knowledge.

Schraw and Moshman (1995) described the regulation of cognition as "metacognitive activities that help control one's thinking or learning" [7]. More specifically, the authors proposed three components of the regulatory skills: namely, (1) planning, (2) monitoring, and (3) evaluating. Planning refers to individuals' ability to select appropriate strategies and allocating available resources. Monitoring refers to "on-line awareness of comprehension and task performance"; in other words, it is individuals" ability to accurately observe their current performance. Evaluating refers to "appraising the products and regulatory processes of one's learning".

Similarly, but more specifically, Schraw and Dennison (1994) [8] suggested five different regulatory roles of metacognition: namely, (1) planning, (2) information management, (3) monitoring, (4) debugging, and (5) evaluating. Planning refers to individuals' ability to set goals and to appropriately allocate resources prior to performing a task or learning. Information management is the usage of technologies and strategies to better organize, refine, summarize, and selectively focus information. Monitoring is being aware of the task and performance processes. Debugging refers to using a strategy to correct errors in understanding and performance. Evaluating is to analyze the effectiveness of performance as well as strategies applied after preforming the task. In short, the regulatory skills of metacognition refer to individuals' ability to plan, manage, monitor, debug, and evaluate the available resources to perform a given task and learning. 
The As aforementioned, metacognition consists of individuals' ability to become aware of their own information processing accurately and subjectively (i.e., the knowledge of cognition) and controlling their thinking process (i.e., regulation of cognition). According to Schoenfeld (2016) [9] and Siagan et al., (2019) [10], these metacognitive skills and strategies can help learners properly apply acquired knowledge to solve given tasks and problems. In other words, those with a high level of metacognition can better acknowledge when to implement their metacognitive strategies, and are better able to choose the proper methods and alternatives for a problem-solving situation [11] than those without metacognitive skills.

Problem-solving skills are a necessary qualification for pre-service teachers as they are likely to encounter classroom circumstances in which unpredictably dynamic incidents occur [12]. Rote memorization of textbook contents would not be sufficient for them to generate solutions. Novice teachers would find most of the on-field problems complicated to solve with the amount of knowledge they would possess by the time they advance to the teaching field. In order for individuals to overcome such obstacles, Dewey (1909) [13] proposed that they need to observe each situation, consider the definition as well as the difficulties of the problems, and derive

alternatives that can result in solutions. Such problem-solving processes are closely linked to metacognitive skills and methods, in a sense that individuals monitor and control their own thoughts. Metacognition is an aspect related to gaining information and utilizing them to cope with surrounding circumstances. Because student learners with a high level of metacognition are more likely to advance their academic performance than those without it, measuring metacognitive accuracy can be an initial stage to better student performance.

Fortunately, Frith (2012) [14] suggested that metacognition is a feature that can be possibly improved throughout explicit training. The author proposed that individuals' metacognition is like a blank slate at the beginning of their lifespan, and is largely determined by social interactions. One can argue that providing learners with proper environments where a series of planned training involving collective discussions may result in enhanced level of metacognitive skills. Furthermore, Frith emphasized that the improvement of explicit metacognition can foster sharing own experiences of action with others, allowing potentially better joint decision, leading to improvement of individual perception of the world.

\subsection{Research questions}

The followings contain the three questions that the researcher is attempting to answer throughout the study.

Research Question 1: To what extend do college student participants demonstrate their metacognitive accuracy regarding their academic performance?

Research Question 2: Do college student participants tend to demonstrate overconfidence or under-confidence regarding their academic performance?

Research Question 3: What opinions and thoughts do college student participants have regarding utilization of metacognitive accuracy for their academic performance?

\section{Methods}

\subsection{Study setting and procedures}

The study procedure was divided into three major Stages. On Stage 1, all student participants were asked to predict their midterm exam score prior to taking the exam in October, 2020; the total score was 25. On Stage 2, the instructor delivered a series of lectures on metacognitive skills, why these skills are necessary, and how their metacognitive accuracy can improve. On 
Stage 3, similarly to Stage 1, all student participants were asked to predict their final exam score prior to taking the exam in December, 2020; the total score was 35.

In order to measure students' metacognitive accuracy regarding their academic performance, the study had taken its place in a four-year university located in a metropolitan city in South Korea. A total of 48 freshman pre-service teachers of department of early childhood education participated in a course entitled "Educational Psychology". The study was conducted during the Fall 2020 semester - more particularly, between October and December (between Week 8 and Week 15).

Additionally, due to the widespread of the novel coronavirus disease (COVID-19) and social distancing restrictions enforced by the Korean government, five (5) out of eight (8) classes, including final exam were conducted under an online setting using Zoom conferences. Three (3) out of eight (8) classes, including the midterm exam were conducted in an offline classroom setting, following strict COVID-19 prevention guidelines, including wearing masks, checking temperature, applying hand sanitizer, and keeping social distances.

\subsection{Study tools}

The study implemented two study tools: a question survey and an open-ended questionnaire. The question survey asked the student participants to predict their performance on both midterm and final exams, what score they wish to attain, and how confident they were regarding their estimated prediction would be accurate. The open-ended questionnaire was provided to the student participants after final exam was over, asking whether they found the discrepancy surprising, what insights they obtained (if there were any), and their confidence level of applying metacognitive skills they might have attained from the study. Details of the question contents that the student participants received are introduced in the Appendixes. Additionally, two experts in the relevant field had validated the questions applied in the study.

\section{Results}

\subsubsection{Question survey}

[Table 1], which contains preliminary statistics about the student participants' performances, showed that the difference between their predicted and actual scores on midterm exam was 3.79 , demonstrating slightly overconfidence, and those on final exam was +1.62 demonstrating slightly under-confidence. The difference that student participants showed on the final was smaller than that of midterm exam. Also, the confidence level slightly reduced from the midterm $(\mathrm{M}=5.42, \mathrm{SD}=1.43)$ to the final exam $(\mathrm{M}=4.46, \mathrm{SD}=1.72)$.

Table 1. Student participants' prediction and actual scores

\begin{tabular}{|c|c|c|c|c|c|c|c|}
\hline \multicolumn{2}{|c|}{ Midterm Exam (N=48) in October, 2020 } & \multicolumn{3}{c|}{ Final Exam (N=48) in December, 2020} \\
\hline $\begin{array}{c}\text { Prediction } \\
\text { (out of 25) }\end{array}$ & $\begin{array}{c}\text { Actual } \\
\text { Score } \\
\text { (out of 25) }\end{array}$ & Difference & $\begin{array}{c}\text { Confidence } \\
\text { Level } \\
\text { (out of 7) }\end{array}$ & $\begin{array}{c}\text { Prediction } \\
\text { (out of 35) }\end{array}$ & $\begin{array}{c}\text { Actual } \\
\text { Score } \\
\text { (out of 35) }\end{array}$ & Difference & $\begin{array}{c}\text { Confidence } \\
\text { Level } \\
\text { (out of 7) }\end{array}$ \\
\hline $\begin{array}{c}\text { M=23.31, } \\
\text { S.D.=1.92 }\end{array}$ & $\begin{array}{c}\text { S=19.52 } \\
\text { S.D.=2.33 }\end{array}$ & -3.79 & $\begin{array}{c}\text { M=5.42 } \\
\text { S.D.=1.43 }\end{array}$ & $\begin{array}{c}\text { M=28.42 } \\
\text { S.D.=3.58 }\end{array}$ & $\begin{array}{c}\text { M=30.04 } \\
\text { S.D.=3.22 }\end{array}$ & +1.62 & $\begin{array}{c}\text { M=4.46 } \\
\text { S.D.=1.72 }\end{array}$ \\
\hline
\end{tabular}




\subsubsection{Open-ended questionnaire}

The following paragraphs contain notable comments that the participant students provided regarding their metacognitive skills and relevant experiences.

- "I thought I knew what I was going to get in almost every exam, but it was a surprising experience to find out that I could be wrong: especially for the exams that I thought I would almost fail" - Student 25

- "Having much confidence is not always a good thing. Having not enough confidence is not a good thing, either" - Student 36

- "When the professor taught me about metacognition, I simply thought that it was about knowing myself, nothing more. Now I'm confident that can better predict my [exam] scores next time." - Student 10

- "I want to predict my [exam] score for my other classes, too. The chances are that I [my prediction] will get closer and closer [to the actual score]." - Student 37

- "This is not something I learned when I was in high school. When I found that my guess was totally different from the result, I could hardly believe it. I learned that knowing my score can help me better prepare for the tests next time." - Student 6

- "Confidence is important, but that's not everything I needed. I found that I spent unnecessarily too much time on reading what I already knew. For the next semester, I'll study more of what I don't know' - Student 7

\section{Discussion}

\subsection{Discussion}

The study attempted to investigate to what extend can pre-service teachers accurately predict their examination performance, particularly on midterm and final during a semester. The smaller differences the student participants show, the better metacognitive accuracy they demonstrate. The results showed that the student participants' metacognitive accuracy moderately improved (from difference of -.3 .79 to +1.62 ) after the instructor had delivered a series of lectures on metacognitive. It was also noticeable that the students' prediction shifted from over-confidence to under-confidence. In other words, the student participants' predicted score prior to taking the midterm exam was moderately higher than their actual scores, and the reverse was the case for the final exam. The student participants' confidence scores on a Likert scale of seven (7), it dropped from 5.42 to 4.46 .

The student participants' written responses regarding the study's practice revealed that the majority of them found their results unanticipated. In general, most of them appeared to expect higher scores on the midterm, and they exhibited a low level of metacognitive accuracy. On the other hand, their responses also show that they are more confident in demonstrating more refined metacognitive accuracy for the future examinations.

\subsection{Conclusions}

Not only do instructors in higher education need to effectively deliver content knowledge, they are also encouraged to emphasize the mechanism of metacognitive accuracy and how useful the skill could be. Discussing with the students regarding what benefits they can earn and what losses they can encounter by having a low level of metacognition could stimulate their motivation for improving metacognitive skills. Also, it should be noted that the study aims 
to provide preliminary information regarding college students' metacognitive awareness and its analyses.

The first limitation of the study is that the implementation of lectures regarding metacognition was not adequately long enough to have the student participants fully attain metacognitive skills. In the future studies, more frequent and in-depth lectures on metacognition might yield a more refined metacognitive skill among the student participants.

The second limitation is regarding the questionnaire. Regrettably, the instructor did not ask the students about their experience on the metacognition lectures. Students' written responses regarding their understanding of metacognitive skills as well as its importance might have generated more in-depth insights about, they perceive metacognitive accuracy.

The third limitation is about the statistical analysis of the study. The figures introduced in the study was merely preliminary data, making it difficult to examine students' experience and opinions in a greater detail. Additionally, the study failed to provide information regarding external factors that could possibly affect metacognitive analysis.

Researchers interested in this theme may develop a program that is particularly designed to foster college students' metacognitive skills. It would be a notable idea to collect students' qualitative data (e.g., written responses and verbal discussions) to more deeply analyze their demands and understanding. Future researchers may use the current study's findings as a stepping stone to further develop designs that better suit college students' needs to enhance their metacognitive accuracy.

\section{Appendixes}

\subsection{Appendix A: Question survey}

The student participants received the following question survey regarding their performance prediction on each of midterm and final exams.

Table 2. Question survey

\begin{tabular}{|c|c|c|}
\hline \multirow{3}{*}{ Midterm Exam } & Question 1 & Out of 25 points, what score do you think you will get? \\
\hline & Question 2 & Out of 25 points, what score do you wish to get? \\
\hline & Question 3 & $\begin{array}{c}\text { On a scale of } 1 \text { to } 7(1=\text { not at all, } 4=\text { moderate, } 7=\text { very much), how } \\
\text { confident are you that your prediction will be correct in terms of the } \\
\text { midterm exam score? }\end{array}$ \\
\hline \multirow{3}{*}{ Final Exam } & Question 1 & Out of 35 points, what score do you think you will get? \\
\hline & Question 2 & Out of 35 points, what score do you wish to get? \\
\hline & Question 3 & $\begin{array}{c}\text { On a scale of } 1 \text { to } 7(1=\text { not at all, } 4=\text { moderate, } 7=\text { very much), how } \\
\text { confident are you that your prediction will be correct in terms of the final } \\
\text { exam score? }\end{array}$ \\
\hline
\end{tabular}

\subsection{Appendix B: Open-ended questions}

The student participants received the following open-ended questions regarding their metacognitive accuracy on each of midterm and final exams. 
Table 3. Open-ended questions

\begin{tabular}{|c|c|c|}
\hline \multirow{3}{*}{ Midterm Exam } & Question 1 & $\begin{array}{l}\text { Did the actual score of the midterm exam somewhat shock you? If yes, } \\
\text { why do you think so? }\end{array}$ \\
\hline & Question 2 & $\begin{array}{c}\text { What insights were you able to attain by realizing the "gap" between } \\
\text { your prediction and the actual score, if there was any? }\end{array}$ \\
\hline & Question 3 & $\begin{array}{l}\text { How confident are you in terms of applying your metacognitive skills for } \\
\text { next semester's exams? }\end{array}$ \\
\hline \multirow{3}{*}{ Final Exam } & Question 1 & $\begin{array}{l}\text { Did the actual score of the final exam somewhat shock you? If yes, why } \\
\text { do you think so? }\end{array}$ \\
\hline & Question 2 & $\begin{array}{c}\text { What insights were you able to attain by realizing the "gap" between } \\
\text { your prediction and the actual score, if there was any? }\end{array}$ \\
\hline & Question 3 & $\begin{array}{l}\text { How confident are you in terms of applying your metacognitive skills for } \\
\text { next semester's exams? }\end{array}$ \\
\hline
\end{tabular}

\section{References}

[1] J. H. Flavell, "Metacognition and cognitive monitoring: A new area of cognitive-developmental inquiry," American Psychologist, vol.34, no.10, pp.906-911, (1979)

[2] J. Metcalfe, "Metacognitive judgments and control of study, current directions in psychological science," vol.18, no.3, pp.159-163, (2009)

[3] J. Metcalfe and B. Finn, "Evidence that judgments of learning are causally related to study choice," Psychonomic Bulletin and Review, vol.15, no.1, pp.174-179, (2008)

[4] J. Goodman-Delahunty, P.A. Granhag, M. Hartwig, and E.F. Loftus, “Insightful or wishful: Lawyers' ability to predict case outcomes," Psychology, Public Policy, and Law, vol.16, no.2, pp.133-157, (2010)

[5] J. H. Flavell, A. G. Friedrichs, and J. D. Hoyt, "Developmental changes in memorization processes," Cognitive Psychology,” vol.1, no.4, pp.324-340, (1970)

[6] A. A. Callender, A. M. Franco-Watkins, and A. S. Roberts, "Improving metacognition in the classroom through instruction, training, and feedback," Metacognition and Learning, vol.11, no.2, pp.215-235, (2016)

[7] G. Schraw and D. Moshman, "Metacognitive theories," Educational Psychology Review, vol.7, pp.351-371, (1995)

[8] G. Schraw and R. S. Dennison, "Metacognitive theories," Educational Psychology Review, vol.19, pp.460-475, (1994)

[9] A. H. Schoenfeld, "Learning to think mathematically: Problem solving, metacognition, and sense making in mathematics," Journal of Education, vol.196, no.2, pp.1-38, (2016)

[10] M. V. Siagan, S. Sarahig, and B. Sinaga, "Development of learning materials oriented on problem-based learning model to improve students' mathematical problem-solving ability and metacognition ability," International Electronic Journal of Mathematics Education, vol.14, no.2, pp.331-340, (2019)

[11] Y. Safari and H. Meskini, "The effect of metacognitive instruction on problem solving skills in Iranian students of health sciences," Global Journal of Health Science, vol.8, no.1, pp.150-156, (2016)

[12] V. Halamish, "Pre-service and in-service teachers' metacognitive knowledge of learning strategies," Frontiers in Psychology, vol.9, pp.2512-2523, (2018)

[13] J. Dewey, "Symposium on the purpose and organization of physics teaching in secondary schools," School Science and Mathematics, vol.9, no.3, pp.291-292, (1909)

[14] C. D. Frith, "The role of metacognition in human social interactions," Philosophical Transactions of the Royal Society B: Biological Sciences, vol.367, pp.2213-2223, (2012) 


\section{Author}

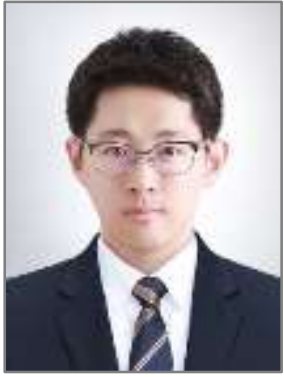

\section{Pyong Ho Kim, Ph.D.}

The author received his master's (Ed.M.) and doctoral (Ph.D.) degrees from Teachers College, Columbia University in New York, USA. He currently teaches and conducts researches in Seoul Women's University in South Korea. His main research interests include metacognition, students' emotional regulation, online discussion, college students' class participation, and higher education. 